\title{
Evaluating the Quality of Social Media in an Educational Context
}

\author{
http://dx.doi.org/ijet.v6i3.1732 \\ K. Silius, M. Kailanto and A-M. Tervakari \\ Tampere University of Technology, Tampere, Finland
}

\begin{abstract}
Social media enhanced learning systems bring new challenges to evaluate learning environments. Many features are common with any web-based services and can be evaluated with common criteria. But with social media services users can also contribute content, change opinions and create communities for different needs, which bring new dimensions to a quality evaluation. This research focused on finding out which are the most important characters and functions in social media enhanced learning system in the context of higher education. The paper also reports the former research results that were used as a background for this study. Earlier researches were carried out in 2008-2009 and they focused on how to evaluate social media services, what are the students' expectations and what motivates them to use social media services in higher educational context.
\end{abstract}

Index Terms-Social media service; higher education; educational technology; quality evaluation; web-based service.

\section{INTRODUCTION}

In social media service users can contribute content, change opinions and create communities for different needs. These features among others bring a new dimension to evaluating social media services, what features make a social media service of high quality. To help evaluators to pay attention to the critical factors of quality of social media services the Web Service Quality (WeSQu) evaluation tool was developed at Hypermedia Laboratory of Tampere University of Technology (TUT).

This paper presents the results of different phases of research conducted in 2008-2010. Firstly a social media service evaluation tool called WeSQu was made based on a literature survey and it was tested how easy it is to use and how well it covers different features of social media services. Then with two different surveys students were asked, what are the main characteristics of a social media enhanced learning system and what motivates students to use social media services in an educational context. The first survey was carried out in spring 2009 to ascertain what kind of characteristics and functions are mentioned by students as pleasant or unpleasant in social media enhanced learning systems in the context of higher education, and what kind of value added there should be when using social media enhanced learning systems. The second survey was carried out in autumn 2009 to ascertain what characteristics and functions motivate students to use a social media enhanced learning system called TUT Circle (http://www.tut.fi/piiri) in the context of higher education.
Finally, based on the results of these researches, a list of social media service related features was made and students were asked to address the most important and least important features from the list. All in all the research aimed at getting an understanding of what are students' expectations for social media services in an higher educational context and identify what are the critical features and factors when using social media enhanced learning systems.

\section{SOCIAL MEdia SERVICES}

The use of social media services (like Facebook, YouTube and blogs) has exploded during last years. Social media services can be divided into six categories: content creation and publishing, content sharing, social network sites, collaborative productions, virtual worlds and add-ons. In this definition traditional discussion forums and IRC are excluded. The same services can also be defined from the perspective of networking and creating connections. There the basis lies in Social Networking Sites (SNS), which usually consist of public or partly public profiles within a limited system, a list of other users the user is connected to and the possibility to view other users' lists of connections [1, 2].

Utilization of social media services for educational purposes has also become increasingly popular. Social media enhanced learning systems allow students to participate in educational online communities by creating, manipulating and sharing content online, communicating and exchanging opinions, connecting with each other, establishing social networks and creating communities for different needs. In community groups students can collaboratively e.g. chat, write news, manage events, write blogs, posts and edit wiki pages and share resources (files, images, videos etc.).

Interaction and collaboration between students depends, among other things, on a sense of community. According to [3] a sense of community is composed of four features: 1) feelings of membership (i.e., a member has a feeling of belonging to, and identifying with the group), 2) feelings of influence (i.e., a member has feelings of having influence on and being influenced by the community that emerge from enforcing and challenging norms within the group), 3) feelings of reinforcement of needs (i.e., a member feels support from others, has status in the group, and meets other people's needs while having his/her own needs met) and 4) feelings of shared emotional connection (i.e., members feel having a relationship and a shared connection with others due to frequent and high quality interaction) [3]. 
It has been suggested that one reason for students' motivation to study is belonging into community of discipline: online communities have been noticed to enhance a sense of belonging and strengthen social contacts and furthermore learning. The usage of social media enhanced learning systems in teaching and studying is rational because earlier social aspects are not utilized in many cases at all in official learning environments [4]. Online communities make visible the social networks that already exist [2]. From a student's point of view one reason to use social media enhanced systems is to combine studies and extracurricular activities.

Social media services pose new challenges in evaluating web-based services and defining what makes a high quality service. It is necessary to pay attention to how social media service supports users to participate in a community and to feel a sense of belonging when evaluating the overall quality of social media services especially in an educational context.

\section{DeVElopment AND EVAluation OF WeSQU TOOL}

WeSQu is a web-based evaluation tool for web-based services (http://hlab.ee.tut.fi/wesqu, in Finnish). It is an updated version of ARVO evaluation tool which was developed at Hypermedia Laboratory at TUT before social media became popular. In $2008 \mathrm{WeSQu}$ was created by updating old questions of ARVO tool and adding new criteria to cover the characteristics that social media services have compared to traditional web-based services. WeSQu comprises ten categories and over 400 questions that help to evaluate quality in different kinds of websites. The criteria - including questions and their arguments were developed on the basis of a background theory, which is based on research in HCI (human-computer interaction), psychology and pedagogy as well as on evaluation research, which has its roots in the theory of usefulness of computer systems. The evaluation framework of usefulness includes issues like usability, added value, accessibility and informational quality of web-based services [5, 6, 7].

Usability means that the user interface of a web-based service must be easy and effective to use so that the user can concentrate on the information content instead of the interface. When a web-based service, like any software, is usable it is easy and efficient to use, easy to remember, has few errors and is subjectively pleasing [7]. The added value of web-based services can be evaluated as in conventional services. Is there something special or something new for users [6]? An essential part of quality is also accessibility, because web design today is designed for individuals with different abilities in various contexts with different devices $[8,9]$. The fourth part of quality is the informational quality. To be of high quality the informational content of a web-based service should meet the five main criteria: accuracy, authority, objectivity, currency and coverage [10,11, 12].

For developing the background theory of WeSQu tool, a literature survey was made during autumn 2008 to find what features form the quality criteria for evaluating special features in social media services. The survey consisted mainly of scientific publications found through ACM Portal, IEEE Explore and Scirus databases as well as Finnish university libraries' databases. The results of the survey were analyzed and the criteria and questions for evaluating special features of social media services were formed through theme analysis [13]. The new criteria can be divided into five categories: privacy and security, information reliability, supporting navigation, accessibility and motivating the user (see Table 1).

Nowadays WeSQu tool covers the following ten sections: presenting information, reliability of information, visual design, readability of text, media elements, supporting navigation, technical implementation, security and privacy, accessibility and motivating the user. To find out which degree a particular field has reached, the evaluator has to answer several questions (see Fig. 1). For minimizing subjective evaluation the questions have been modified so that the evaluator does not have to think to what degree a particular criterion has been reached. The evaluator answers to simple questions by choosing one of the alternatives: always, often, sometimes, rarely or never. After the evaluation the evaluator can have a report of the results of the evaluation. This report is composed of the overall quality profile of the web-based service, a summary of the good features and guidelines on how to develop this particular web-based service $[14,15]$.

Sections that include features of social media services in WeSQu tool have been tested in different ways. At first, the tool was tested with a combination of pluralistic usability walk-through and a group interview with three hypermedia students and experts [13]. Secondly the contents of 'the Security and Privacy' and 'the Motivating the User' sections were evaluated by 34 hypermedia students. The students were also asked to evaluate the use of WeSQu tool. The students wrote short essays on their findings, which were analyzed.

The aim of the two tests was to find out if the criteria covered the special features in social media services and if the criteria and the questions were understandable. The tests produced similar results. According to the results nothing major was missing from the criteria. However, questions related to the implementation are not included in WeSQu. This leaves some important facts out of the

TABLE I.

QUALITY CRITERIA IN SOCIAL MEDIA SERVICES WITH THEIR CATEGORIES IN WESQU TOOL

\begin{tabular}{|c|c|}
\hline Category & Criterion \\
\hline \multirow{5}{*}{$\begin{array}{l}\text { Privacy and } \\
\text { Security }\end{array}$} & User security issues \\
\hline & Reasonable use of cookies \\
\hline & $\begin{array}{l}\text { Guiding user to good practices in privacy and } \\
\text { security issues }\end{array}$ \\
\hline & Enabling different privacy levels \\
\hline & Creating and managing digital identity \\
\hline \multirow{2}{*}{$\begin{array}{l}\text { Information } \\
\text { Reliability }\end{array}$} & Users’ reliability \\
\hline & Reliability of user generated content \\
\hline \multirow{4}{*}{$\begin{array}{l}\text { Supporting } \\
\text { Navigation }\end{array}$} & Selecting the right classification system \\
\hline & Management of tags \\
\hline & Supporting social browsing and navigation \\
\hline & Utilizing feeds \\
\hline Accessibility & $\begin{array}{l}\text { Enabling adding accessible content and } \\
\text { accessible content adding }\end{array}$ \\
\hline \multirow{4}{*}{ Motivating the User } & Rewarding and motivating the user \\
\hline & $\begin{array}{l}\text { Taking into account all users (from beginners } \\
\text { to advanced) }\end{array}$ \\
\hline & Personalization and maintaining interest \\
\hline & Making it easy to follow what is going on \\
\hline
\end{tabular}




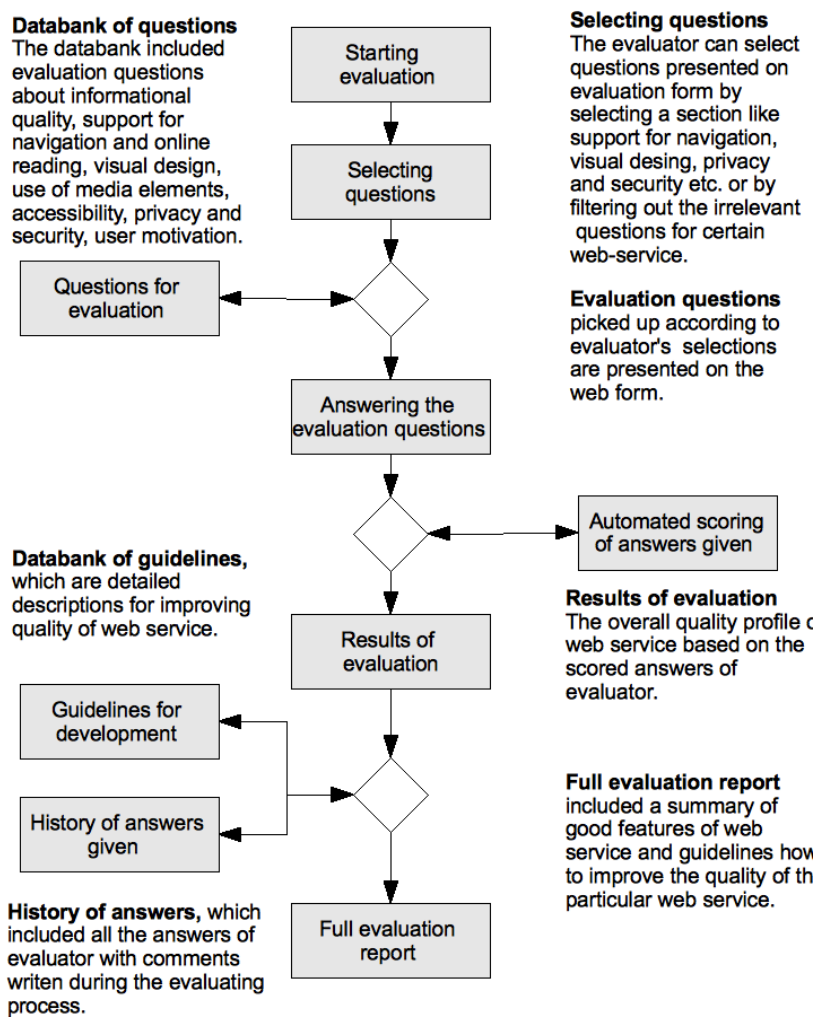

Figure 1. WeSQu tool helps evaluators to control the evaluation process and gather essential information for improving the quality of a particular web service. Modified from the presentation of the ARVO tool $[13,14]$.

evaluation in 'Security and privacy' section such as how the service provider takes care of different security issues. Also, one new criterion was suggested under the 'Motivating the user' section.

The criteria and questions were mainly written so that they could be interpreted and understood correctly by nonprofessionals but some of the used terms needed some sort of expertise on the subject (mainly in security and privacy section) [13]. In addition, according to the results some other methods should be used in addition to WeSQu tool when evaluating how social media service motivates users. The facts that motivate users to use a certain social media service varies a lot depending on purpose of the use and context. In general WeSQu tool was found easy to use and useful in the evaluation process.

\section{Main Characteristics And Motivating Factors OF SOCIAL ENHANCED LEARNING SYSTEMS}

To get an overview of features and factors that are the most relevant in higher educational context two surveys were made in 2009. The first survey aimed at finding out what students thought were pleasant and unpleasant when using social media services in an educational context. The purpose of the second survey was to find out what are the factors that motivate users to act in social media services related to their studies and student life. The results of these surveys are reported in this chapter.

\section{A. Survey of the Main Charasteristics of Social Enhanced Learning Systems}

In spring 2009 data was collected from ten hypermedia students regarded as early adopters using insight as a method to find out what characteristics and functions are mentioned by students as pleasant or unpleasant in social media enhanced learning systems in the context of higher education, and what kind of value added there should be in using social media enhanced learning systems.

The students were asked to complete two different frame stories, positive and negative ones, by writing essays. The students generally thought that a social networking service in the context of studying needs some particular purpose and this added value must become clear to every user. It was also underlined that the quality of a social networking service depends on the quality of the community within it. An educational online community should be focused on networking and social interaction, university related information sharing and study support, as well as connecting users with similar interests with enriched user profile. Students also prefer a service if it is free and all activity is voluntary. In the answers students expected positive user experience which depends on functionalities and content. In general every well designed and developed system with good usability, accessibility and overall technical sustainability supports users in using a web-based service. Visually pleasant and trendy interface also pleases students [4].

\section{B. Survey of Students' Motivations for Using Social Media Enhanced Learning Systems, Case: TUT Circle}

The second survey was carried out in autumn 2009 to find out what characteristics and functions motivate students to use social media enhanced learning systems in the context of higher education. The data was collected from 38 hypermedia students also regarded as early adopters.

At first, the students were asked to sign up for TUT Circle, which is a web-based environment for students offering customized tools for enhancing social aspects of student life at TUT. TUT Circle provides all the common tools for interaction between individual users. Every user has her/his own profile where information about user him/her can be shared with others. A user can also ask some other user to be his/her friend in TUT Circle. The friend requests must be accepted before the relationship is formed. Users can create groups and in a group members can chat, write news, manage events, write blog posts, edit wiki pages collaboratively and share different kind of resources. All content in TUT Circle can be tagged with keywords.

Secondly, the students were asked to analyze aspects, functions, or features motivating users to use the service by using WeSQu tool and its Motivating the User section, and write short essays on their findings, which were analyzed [4].

The following issues were highlighted in students' answers [5]:

- New features should be added to the networking service bit by bit. It was considered that beginning system usage is easier if a platform is fairly simple at first.

- A networking service is a suitable tool for promoting different events for students. The option to add geographic information to the Google Maps widget was deemed very motivating. 
- At profile level it was appreciated that a user can give only the personal information he/she wants to share.

- It was motivating to follow friends' events, content and profile information.

- E-mail messages about new features and content feeds were deemed to increase the participation in content production in the social networking service. In addition, content feeds in a user dashboard were considered to be motivating.

- A function like or dislike content and features was desired, likewise listings of the most popular content, users, actions, etc.

- RSS feeds were considered convenient functionalities.

- Some students emphasized the importance of anonymity in web community activity.

Overall it was observed that the nature and purposes of social media enhanced learning systems affect students' motivations to use the systems. This challenges universities to provide modern systems with high quality to support students to study and to be members of formal and informal communities at university.

\section{SuRVEY OF THE MOST AND LEAST IMPORTANT FEATURES IN AN EDUCATIONAL CONTEXTS}

The latest research was carried out in autumn 2010 and it focused on finding which of the criteria identified earlier are most and least important in students' opinion in the educational context. A survey was executed to elicit answers from hypermedia students.

The questionnaire for the survey was mostly based on the themes described as criteria in WeSQu tool in Table 1. Each criterion in WeSQu has specific questions on features related to it and those questions were converted into statements for the questionnaire. 'Selecting the right classification system' criterion was removed because it proved hard to understand without further information about the subject. In addition to the themes from WeSQu tool two other themes 'General features' and 'Communication between other members of the community' were added to the questionnaire. The features for these two themes were formed on the basis of the results from the previous research in [4].

The students were advised to participate in the web survey that asked them to choose the ten most and least important features from a total of 89 features. Forty hypermedia students answered the survey as a part of their course assignment on a course where they learned how to evaluate different types of web sites from different points of view. The students were asked to consider the features in the higher educational context and no specific social media service was pointed out to them. This may have affected the results because some students might have thought more of web-based services related to studying and others more generally of the social media services that they also use in their free time in the university context. The answerers also pointed out that the TOP10 features were hard to select because many of the features were considered important.

From the results percentages were calculated of how many students thought each feature was important and not important. Table 2 presents all features mentioned as the most important by at least $25 \%$ of respondents. Table 3 presents the features thought to be unimportant in the educational context by at least $25 \%$ of the students responding to the survey.

According to the results the most important feature of the social media service in educational context is usability. Seventy three per cent of students ranked the feature " 1 . The service is easy to use.” among the ten most important features. Features related to communication and collaboration were also ranked high. About one out three of the students thought that features like " 2 . It is possible to contact other users both privately and publicly.", "4. Users can produce content together." and " 11 . It is possible to create connections to other users in the web service.” were important for a social media service. The third issue which seemed to be important from the viewpoint of the students was privacy and security. Five features (features no. 3, 5, 7, 8 and 9) related to privacy and security issues were ranked among the eleven most important features. According to one out three of students the option to inform about content with poor quality was a relevant feature of the social media services. See Table 2.

To know who is producing content of high quality or in large quantities was not important for the students. Sixtyfive per cent of them were thinking that the TOP list of productive users (feature no. 1) is the least important feature of social media services in the educational context.

Two other features related to connections between contents and the users (features no. 3 and 8 ) were also ranked among the ten least important features. In addition, the features which seemed to be less important according to the students' answers were related to supporting the

TABLE II.

MOST IMPORTANT FEATURES ( 25\% INCLUDED THEM IN THEIR ANSWERS)

\begin{tabular}{|c|c|c|}
\hline Feature & $\%$ & Theme \\
\hline 1. Web service is easy to use. & 73 & General features \\
\hline $\begin{array}{l}\text { 2. It is possible to contact other } \\
\text { users both privately and publicly. }\end{array}$ & 38 & $\begin{array}{l}\text { Communication } \\
\text { between members of } \\
\text { the community }\end{array}$ \\
\hline $\begin{array}{l}\text { 3. When user registers for the web- } \\
\text { based service he has to give only } \\
\text { information that is necessary for } \\
\text { the realization of the service. }\end{array}$ & 35 & $\begin{array}{l}\text { Guiding user to good } \\
\text { practices in privacy } \\
\text { and security issues }\end{array}$ \\
\hline $\begin{array}{l}\text { 4. Users can produce content } \\
\text { together. }\end{array}$ & 33 & General features \\
\hline $\begin{array}{l}\text { 5. Signing-in to the service is } \\
\text { performed over a secure } \\
\text { connection (such as SSL). }\end{array}$ & 33 & $\begin{array}{l}\text { Use of cookies and } \\
\text { secure connection }\end{array}$ \\
\hline $\begin{array}{l}\text { 6. It is possible for users to inform } \\
\text { about bad or inappropriate content. }\end{array}$ & 33 & $\begin{array}{l}\text { Reliability of user } \\
\text { generated content }\end{array}$ \\
\hline $\begin{array}{l}\text { 7. Inappropriate content and spam } \\
\text { are removed from the service. }\end{array}$ & 33 & $\begin{array}{l}\text { Personalization and } \\
\text { maintaining interest }\end{array}$ \\
\hline $\begin{array}{l}\text { 8. It is possible for the user to act } \\
\text { anonymously in the service if the } \\
\text { identification is not relevant for the } \\
\text { operation of the service. }\end{array}$ & 30 & $\begin{array}{l}\text { Managing } \\
\text { information related to } \\
\text { the user }\end{array}$ \\
\hline $\begin{array}{l}\text { 9. If the user stops using the } \\
\text { service entirely, all the information } \\
\text { related to the user will be deleted. }\end{array}$ & 28 & $\begin{array}{l}\text { Managing } \\
\text { information related to } \\
\text { the user }\end{array}$ \\
\hline $\begin{array}{l}10 \text {. The service is structured so } \\
\text { that it is easy to get an overview of } \\
\text { what the service contains. }\end{array}$ & 28 & $\begin{array}{l}\text { Making it easy to } \\
\text { follow what is going } \\
\text { on }\end{array}$ \\
\hline $\begin{array}{l}\text { 11. It is possible to create } \\
\text { connections to the other users in } \\
\text { the service. }\end{array}$ & 28 & $\begin{array}{l}\text { Communication } \\
\text { between members of } \\
\text { the community }\end{array}$ \\
\hline
\end{tabular}


community (features no. 5, 6, 10 and 11). More than one out three of the students thought that features like " 5 . The service has lots of familiar users" or " 6 . It is possible to comment in public on other users' profiles" are not very important for social media services in the educational context. The students also considered the option to see connections between different users (feature no. 11) or user profiles with updating information (feature no. 10) to be among the least important features of social media services. See Table 3.

There were also two open questions in the survey. The first one was aimed to elicit answers about important matters other than those stated in the list of 89 features. From the answers it could clearly be seen that the features presented in the list were thought to cover the matter well. Yet a few good additional features were pointed out in the open answers:

- A feature where it would be easy for the student to see his state of learning compared to general learning goals.

- The system could connect a user with the same interests or with users doing same exercises on campus.

- Creating student groups for study purposes: doing things together and creating content simultaneously matters.

- There should be integration and interaction with other social media services.

- Following a user's own tracks: for example, comments and exercises done in the past should be easy to locate in the database.

In the second question students analyzed whether only ten most important features could be used to evaluate the quality of a web-based service in an educational context. The answerers were unanimous in that ten most important features were not enough to give an extensive result of the quality. Seventeen answers stated that with just ten features no reliable quality evaluation could be done. Yet 23 students suggested that a suggestive overview of the quality could be gained with a quick list. Some specified in their answers that better results could be attained if there were adjusted top10 lists of features for evaluating different types of social media services. Also the quick checklist was considered to work better for simple social media services that do not have so many functionalities and complex structure. Extending the list up to 20 features was also suggested to improve the accuracy of the evaluation.

\section{DISCUSSION AND CONCLUSION}

This paper concluded results from different researches done at TUT in 2008-2010. The main focus was on identifying the most important characteristics and functions in a social media enhanced learning system in the context of higher education. It also gathers together information on how WeSQu tool suits for evaluating such services.

At their best social media enhanced learning systems offer versatile features to support a learning community to study and teach. Typically social media service provide an opportunity for students to create a profile, make a list of friends, connect with others, send private or public messages to others, create content together, share content,
TABLE III.

LEAST IMPORTANT FEATURES ( 25\% INCLUDED THEM IN THEIR ANSWERS)

\begin{tabular}{|c|c|c|}
\hline Feature & $\%$ & Theme \\
\hline $\begin{array}{l}\text { 1. There is on view a TOP list of } \\
\text { users who have created a lot of } \\
\text { content or content of good quality } \\
\text { to the service. }\end{array}$ & 65 & $\begin{array}{l}\text { Rewarding and } \\
\text { motivating the user }\end{array}$ \\
\hline $\begin{array}{l}\text { 2. It is trendy to use the specific } \\
\text { service. }\end{array}$ & 58 & General features \\
\hline $\begin{array}{l}\text { 3. The service rewards users who } \\
\text { actively produce good content. }\end{array}$ & 43 & $\begin{array}{l}\text { Rewarding and } \\
\text { motivating the user }\end{array}$ \\
\hline $\begin{array}{l}\text { 4. It is possible to attach } \\
\text { geographical information to other } \\
\text { information. }\end{array}$ & 38 & General features \\
\hline $\begin{array}{l}\text { 5. The service has many familiar } \\
\text { users. }\end{array}$ & 38 & General features \\
\hline $\begin{array}{l}\text { 6. It is possible to comment in } \\
\text { public on other users' profiles.. }\end{array}$ & 35 & Users' reliability \\
\hline $\begin{array}{l}\text { 7. Information on the use of } \\
\text { cookies is given in user's native } \\
\text { language. }\end{array}$ & 33 & $\begin{array}{l}\text { Use of cookies and } \\
\text { secure connection }\end{array}$ \\
\hline $\begin{array}{l}\text { 8. The context of the content } \\
\text { shows how many users have seen } \\
\text { the content. }\end{array}$ & 33 & $\begin{array}{l}\text { Reliability of user } \\
\text { generated content }\end{array}$ \\
\hline $\begin{array}{l}\text { 9. CAPTCHA image (used in } \\
\text { registration) has an audio option } \\
\text { available. }\end{array}$ & 33 & Accessibility \\
\hline $\begin{array}{l}\text { 10. User profile does not consist } \\
\text { only of static and rarely updated } \\
\text { information. }\end{array}$ & 30 & $\begin{array}{ll}\text { Creating } & \text { and } \\
\text { managing } & \text { digital } \\
\text { identity } & \end{array}$ \\
\hline $\begin{array}{l}\text { 11. Users have on view two-way } \\
\text { connections between different } \\
\text { users. }\end{array}$ & 28 & Users' reliability \\
\hline $\begin{array}{l}\text { 12. It is possible to get email feeds } \\
\text { from the updated content in the } \\
\text { service. }\end{array}$ & 28 & $\begin{array}{l}\text { Making it easy to } \\
\text { follow what is going } \\
\text { on }\end{array}$ \\
\hline
\end{tabular}

comment each other's content etc. [1, 2]. The social media services should also be usable and accessible with robust technological solutions. The results show that almost three out four of the students (73\%) considered ease of use to be the most important criterion. Usability of the service is important especially in the educational context, so that a user can concentrate on the learning instead of struggling with the interface.

The students at TUT also emphasized that social media services should provide clear added value. The students generally thought that social media enhanced environments in the context of studying need some particular purpose and the added value must become clear to every user. To offer added value in an educational context the social media services should support networking and social interaction and help students to connect with other students with similar interests, for example, users doing the same exercise on campus. The purpose of a social media enhanced learning environment was seen as a system which connects tutors and other students, for example, as exercise partners.

An important aspect to take into account is that the quality of a social networking service depends on the quality of the community within it. The community can offer feelings of membership, influence, reinforcement of needs or feelings of a shared emotional connection [3]. It is also necessary to pay attention to these features when evaluating the overall quality of social media enhanced learning systems. In the context of one's own university the social media enhanced learning environment could at least increase the feeling of fellowship and solidarity. The 
students emphasized the importance of communication and collaboration. The possibility to create connections and send private or public messages to other students or teachers as well as the option to create content together are all essential features in using social media services for educational purposes. Although the option to communicate and interact is important to the students, the number of familiar users in the service or the option to comment on other users' profiles are not mentioned as an important functionality for the students. That could indicate that for the students it is more important to communicate and collaborate to learn than to keep company with friends. Linking together studies and spare time needs active students in the environment.

A new phenomenon related to the students' opinions was the importance of privacy and security. Five out the eleven most important criteria were related to privacy issues. According to the students only that information which is essential for using a web-based service should be required for registration of users, and authentications should always be performed over a secure connection. The students also emphasized that when the authentication is not essential for using a web-based service, the anonymous use of the service should be allowed. The option to remove all personal information from the service when a user stops using the service was important for the students. The increased importance of privacy and security issues could be a consequence of the students' awareness of security and privacy. Students studying technology are usually adept at comprehending and manipulating complex technology and more aware of technological issues than average individuals. The students' concern about their privacy may also have increased because of almost daily news about privacy violation. In any case, the privacy of personal information and also security are crucial issues from the perspective of management and the protection of students' identity in educational institutions. Further research is needed to better understand students' attitudes towards privacy and the connection between those attitudes and their privacy strategies. For example, do students of non-technical fields of study have different attitudes towards privacy and security?

The students also noted the importance of informational quality. From the students' viewpoint it is important that there are some kinds of mechanisms or policies for filtering, marking and removing content of poor quality. However the students considered the criteria related to reliability of user generated content to be one of the least important features. In the students' opinion the rewarding systems or other policies for promoting the production of good quality content and the reliability of the content are not important features. This may be related to the learning culture of the organization. Traditionally the students have created and produced content and delivered it only to the teachers for the evaluation of learning outcomes. It is not common for students to share content with other students.

In technical fields of study students seem to be interested in the possibilities of social media services. Students are increasingly requiring web-based tools for studying as well as freely accessible electronic course materials. Obviously tools provided by social media are attractive to students today and making those tools a part of traditional teaching, studying and learning is rational.
The quality of a social media service is a complex and multidimensional concept and depends highly on the context. The evaluation of social media enhanced environments is a challenge and therefore WeSQu tool was developed. WeSQu tool also makes it easier to evaluate web-based services for people who are not experts with special vocabulary and the evaluation of web-based services or they do not know anything about the implementation. The evaluation process is also much easier and faster with WeSQu tool than for example using lists of heuristics even if an evaluator has used the service a lot. All in all WeSQu tool gives good basic background for evaluating the quality of different types of web-based services and for example helps teachers to pay attention to important facts about the social media service they are planning to use.

The use of social media services in an educational context is an increasing trend and there are many national wide researches going on in Finland. Hypermedia laboratory at TUT is working on different projects founded by the European Social Fund and Finnish Ministry of Education and Culture. During these projects it has been seen that students' attitudes towards social media services in educational context has changed. At first it was seen more of a way to connect with other people during their free time, but now they start to expect the use of social media services more in the studying context. In the future there is plenty of work on how to support student in their learning processes through social media services and how to evaluate the pedagogical aspects in social media systems used in educational context.

\section{REFERENCES}

[1] K. Lietsala and E. Sirkkunen, Social Media - Introduction to the tools and processes of participatory economy. Hypermedia Laboratory Net Series 17. Tampere: Tampere University Press, 2008.

[2] d. m. boyd and N. B. Ellison, "Social network sites: Definition, history, and scholarship," in Journal of Computer-Meditated Communication, vol. 13, no. 1, article 11, 2007.

[3] D. W. McMillan and D. M. Chavis, "Sense of community: A definition and theory," in Journal of Community Psychology, vol. 14, pp. 6-23, no.1, 1986.

[4] K. Silius, T. Miilumäki, J. Huhtamäki, T. Tebest, J. Meriläinen and S. Pohjolainen, "Students' Motivations for Social Media Enhanced Studying and Learning," in Knowledge Management \& E-Learning: An International Journal (KM\&EL), the Special Issue on "Technology Enhanced Learning”, vol. 2, , March 2010.

[5] K. Silius and A.-M. Tervakari, "Variety of quality experiences on web- based courses," in Proc. 7th IEEE International Conference on Advanced Learning Technologies, ICALT. Niigata, Japan, July 2007, J. M. Spector, et al., Eds., 2007.

[6] N. Forsblom and K. Silius, "What is the Added Value of Webbased Learning and Teaching? The Case of Tampere University of Technology,” in New Educational Benefits of ICT in Higher Education Conf. , Rotterdam, The Netherlands, 2002.

[7] J. Nielsen, Usability Engineering. San Diego, CA: Academic Press, 1993.

[8] A. Foley and B. Regan, "Web Design for Accessibility: Policies and Practice," in AACE Journal, vol. 10, pp. 62-80, no. 1, 2002.

[9] S. Burgstahler, "Distance Learning. Universal Design, Universal Access," in AACE Journal, vol. 10, pp. 32-61, no. 1, 2002.

[10] M.-C. Liu, "A Systematic Web-Course Development Process: User- Centered Requirements," in Educational Technology, vol. 41, pp. 15 - 22, no. 6, 2001.

[11] P. R. Albion, "Heuristic evaluation of educational multimedia: from theory to practice," in 16th Annual Conference of the Australasian Society for Computers in Learning in Tertiary Education, ASCILITE. 1999. 
[12] S.-O. Tergan, "Checklists for the evaluation of educational software. Critical review and prospects," in Innovations in Education and Training International, vol. 35, pp. 9-20, no. 1, 1998.

$$
\text { Kailanto, "Yhteisöllisten verkkopalveluiden }
$$
laadukkuuskriteerit,” Master's Thesis. Tampere: Tampere University of Technology, 2009.

[14] K. Silius and A.-M. Tervakari, “An Evaluation of the Usefulness of Web-based Learning Environments. The Evaluation Tool into the Portal of Finnish Virtual University," in International Conference on Network Universities and E-Learning. Proceedings of mENU. Valencia, Spain, V. Peñarrocha, et al., Eds., 2003.

[15] K. Silius, A.-M. Tervakari and S. Pohjolainen, “A Multidisciplinary Tool for the Evaluation of Usability, Pedagogical Usability, Accessibility and Informational Quality of Web-based Courses," in Proceedings of The Eleventh International PEG Conference: Powerful ICT for Teaching and Learning, PEG2003. St. Petersburg, Russia, 2003.

\section{AUTHORS}

K. Silius is with the Hypermedia Laboratory, Tampere University of Technology, Tampere, Finland (e-mail: kirsi.silius@tut.fi).

M. Kailanto is with the Hypermedia Laboratory, Tampere University of Technology, Tampere, Finland (email: meri.kailanto@tut.fi).

A-M. Tervakari is with the Hypermedia Laboratory, Tampere University of Technology, Tampere, Finland (email: anne.tervakari@tut.fi).

This work was supported in part by European Social Fund, North Ostrobothnia Centre for Economic Development, Transport and the Environment. This article is an extended version of a paper presented at the International Conference EDUCON2011, held in April 2011 at PSUT, in Amman, Jordan. It has won the Best Paper Award. Received, June, 30, 2011. Published as resubmitted by the authors August $2^{\text {nd }}, 2011$. 